\title{
The Potential Usefulness of Magnetic Resonance Guided Focused Ultrasound for Obsessive Compulsive Disorders
}

\author{
Hyun Ho Jung, M.D., Ph.D.,' Won Seok Chang, M.D., Se Joo Kim, M.D., Ph.D., ${ }^{1}$ Chan-Hyung Kim, M.D., Ph.D., ${ }^{2}$ \\ Jin Woo Chang, M.D., Ph.D.' \\ Department of Neurosurgery and Brain Research Institute, 'Yonsei University College of Medicine, Seoul, Korea \\ Department of Psychiatry and Institute of Behavioral Science, ${ }^{2}$ Yonsei University College of Medicine, Seoul, Korea
}

Obsessive compulsive disorder is a debilitating condition characterized by recurrent obsessive thoughts and compulsive reactions. A great portion of the obsessive compulsive disorder (OCD) patients are managed successfully with psychiatric treatment such as selective serotonin-reuptake inhibitor and cognitive behavioral psychotherapy, but more than $10 \%$ of patients are remained as nonresponder who needs neurosurgical treatments. These patients are potential candidates for the neurosurgical management. There had been various kind of operation, lesioning such as leucotomy or cingulotomy or capsulotomy or limbic leucotomy, and with advent of stereotaxic approach and technical advances, deep brain stimulation was more chosen by neurosurgeon due to its characteristic of reversibility and adjustability. Gamma knife radiosurgery are also applied to make lesion targeting based on magnetic resonance (MR) imaging, but the complication of adverse radiation effect is not predictable. In the neurosurgical field, MR guided focused ultrasound has advantage of less invasiveness, real-time monitored procedure which is now growing to attempt to apply for various brain disorder. In this review, the neurosurgical treatment modalities for the treatment of OCD will be briefly reviewed and the current state of MR guided focused ultrasound for OCD will be suggested.

Key Words : Obsessive-compulsive disorder - Deep brain stimulation · Psychosurgery · High-intensity focused ultrasound ablation.

\section{BACKGROUND}

Obsessive compulsive disorder (OCD) is a chronic and disabling condition characterized by obsession (intrusive, unwanted thoughts, impulses, images that occur outside of one's control and generate significant anxiety) and compulsion (stereotyped motor, cognitive acts and rituals that are performed in an attempt to relieve the anxiety). Approximately $2 \%$ of the populations are affected, and OCD is one of the most disabling psychiatric disorders ${ }^{3,47}$. A great portion of the patients are managed successfully with psychiatric treatment such as selective serotonin-reuptake inhibitor and cognitive behavioral psychotherapy, but more than $10 \%$ of patients are remained as non-responder who needs neurosurgical treatments ${ }^{41,43)}$.

The imbalance of excitatory and inhibitory loop in corticostriato-thalamo-cortical (CSTC) circuits is thought to be the pathophysiology of $\mathrm{OCD}^{38,44}$. There are multiple CSTC circuits, and the ventral cognitive CSTC circuits, which projects from the anterior and lateral orbitofrontal cortex through the putamen, has been implicated as central to OCD in neuroim-

- Received : May 15, 2017 • Accepted : July 19, 2017

- Address for reprints : Jin Woo Chang, M.D., Ph.D.

Department of Neurosurgery and Brain Research Institute, Yonsei University College of Medicine, 50-1 Yonsei-ro, Seodaemun-gu, Seoul 03722, Korea Tel : +82-2-2228-2159, Fax : +82-2-393-9979, E-mail : jchang@yuhs.ac

This is an Open Access article distributed under the terms of the Creative Commons Attribution Non-Commercial License (http://creativecommons.org/licenses/by-nc/4.0) which permits unrestricted non-commercial use, distribution, and reproduction in any medium, provided the original work is properly cited. 
aging studies ${ }^{36)}$. The cortico-thalamic pathway, which projects from the orbitofrontal cortex to the thalamus through the anterior limb of internal capsule, is excitatory. On the contrary, cortico-straito-thalamic pathway, which projects from the orbitofrontal and prefrontal cortex through the ventral striatum to the thalamus, is inhibitory and should be counterbalanced. So the imbalance results in orbitofrontal cortex loop hyperactivity, and it generates obsessions and related compulsions. Also the dysfunction of dorsal anterior cingulate cortex is another aberrant hypothesis of OCD which has the role of aberrant cognitive control signal specification ${ }^{29)}$. So the neurosurgical targets along these pathways were indicated and to disrupt or regulate the subcircuit by balancing.

The goal of this report is to review the neurosurgical treatment modalities for the treatment of OCD briefly and the current state of magnetic resonance guided focused ultrasound (MRgFUS) for OCD.

\section{REVIEW}

\section{Lesioning procedures}

\section{Cingulotomy}

Since Egas Moniz published his first operation, prefrontal leucotomy, in 1936 and widely used after modified by Walter Freeman and James Watts ${ }^{13)}$, thousands of patients with mental illness had undergone frontal lobe surgery till $1950 \mathrm{~s}^{2}$. Because of the lack of anatomical precision of frontal leucotomy and side effects, the more limited operations were developed as frontal topectomy or undercutting under direct visual inspection or electrocoagulation ${ }^{30,39,42}$. After stimulation of Brodmann area 24 in monkeys which showed autonomic changes of emotional expression and a widespread cortical suppressor effect $^{8)}$, bilateral removal of the anterior part of the cingular gyrus, anterior cingulectomy, was introduced by Whitty et al. ${ }^{48)}$ at 1949. Among 24 patients in their series, four OCD patients showed marked improvements. After that, Foltz and White introduced stereotaxic cingulotomy for the intractable pain patients in 1962, and they reported that the anxiety or depression of the patients were also improved. This impressive result let Ballantine et al. ${ }^{2)}$ do bilateral stereotaxic cingulotomy for 57 patients with mental illness in 1967, and 40 patients were followed up from 3 months to 4 years with variable improvements from 30 patients. In 1972, Laitinen et al. ${ }^{22}$ used stereotaxic frame for the cingulotomy, and radiofrequency was first used in 1990 by Hassenbusch et al. ${ }^{14)}$.

More than 400 patients with OCD underwent bilateral stereotactic radiofrequency cingulotomy since Ballantine's large number reports in $1987^{1)}$. The reported overall success rate were up to $30-40 \%$, and though there were no other major side-effects, some minor complications such as urinary incontinence, decreased libido, weight gain, nightmares, persistent headache, were identified ${ }^{1)}$. Adverse effect after cingulotomy was reported transient and/or mild 14\% and permanent and/ or serious $5.2 \%{ }^{4}$. In our series of cingulotomy for OCD, 17 patients showed 35.0 \pm 3.86 of Yale-Brown obsessive-compulsive scale (Y-BOCS) at preoperative state, and after more than
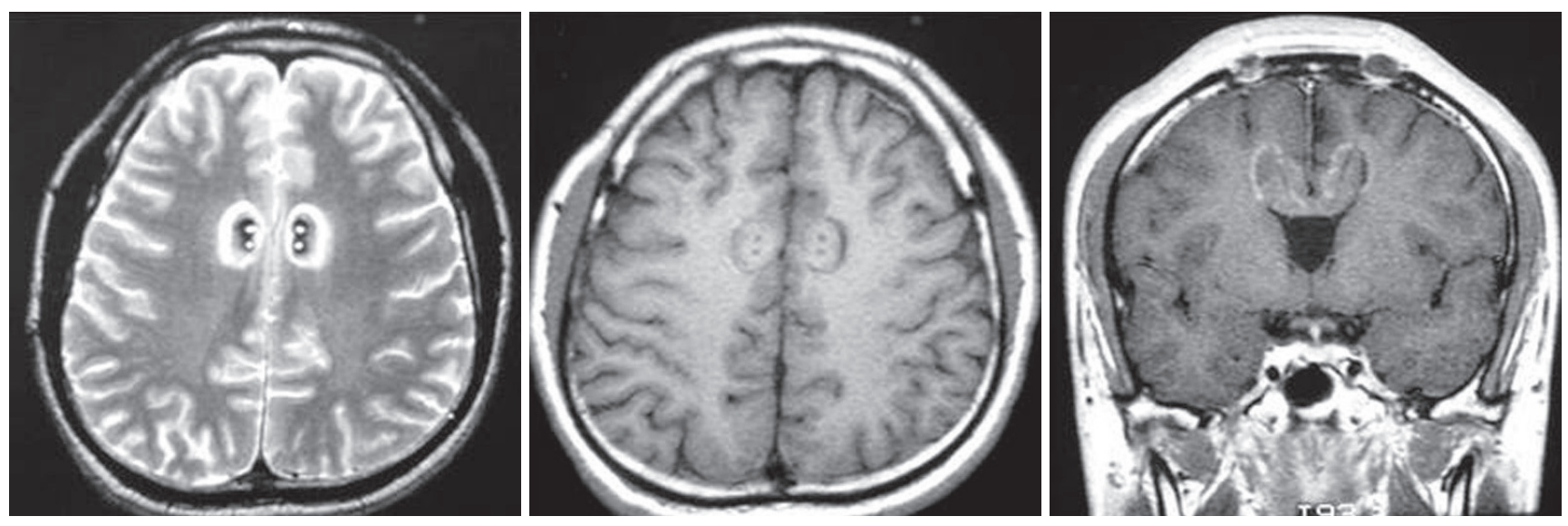

Fig. 1. Magnetic resonance images of bilateral cingulotomy. Four lesions along two tracks were made on both side of the anterior cingulate gyrus. Fifteen $\mathrm{mm}$ posterior to the frontal horn of the lateral ventricle, $2 \mathrm{~mm}$ above the roof of the ventricle and $7 \mathrm{~mm}$ lateral to the midline was targeted, and after lesioning with $85^{\circ} \mathrm{C}$ for 90 seconds at first target, the electrode was withdrawn about $8 \mathrm{~mm}$ to produce second lesion (left : T2WI axial, middle : T1WI axial, right : T1WI coronal section). 
two years of follow-up period, the mean improvement rate of Y-BOCS score were $48 \%$ from the baseline (Fig. 1). All the patients were assessed with neuropsychological test to evaluate any difference of cognitive changes after cingulotomy at 24 months. There were no significant adverse effects observed after operation ${ }^{17)}$. Recent long-term study with a 5 -year mean follow-up with 64 patients showed $47 \%$ of full response (more than $35 \%$ of Y-BOCS improvements) by Sheth et al. ${ }^{40)}$.

\section{Capsulotomy}

To disconnect the fibers from the orbitofrontal cortex to the limbic system which pass through the anterior limb of internal capsule, Talairach in 1949, first introduced the technique of anterior capsulotomy for the psychiatric disorder patients $s^{5)}$. In the 1950s, Leksell ${ }^{23)}$ and Talairach ${ }^{24)}$ modernized the anterior capsulotomy, and the first radiosurgical capsulotomy was done in 1953 with $300 \mathrm{kV}$ X-rays. Lippitz et al. ${ }^{25}$ reported their 22 cases of bilateral thermo-capsulotomy from 1976 to 1989 and during median 8.4 years of follow-up, 9/19 patients showed good outcome. The bilateral thermo-capsulotomy results from recent large study were reported by Oliver et al. ${ }^{35}$ ( $(\mathrm{n}=10)$, Liu et $\mathrm{al}^{26)}(\mathrm{n}=35)$, and D'Astous et al. ${ }^{6}(\mathrm{n}=19)$, and the improvement of Y-BOCS from the baseline was 43.3\% (30 to 17), $80.9 \%$ (21 to 4 ), $31.4 \%$ (35 to 24 ), respectively. Adverse effect after capsulotomy was reported transient and/or mild 56.2\% and permanent and/or serious $21.4 \%{ }^{4)}$.

Capsulotomy using gamma knife radiosurgery was introduced by Leksell which was reported in $1955^{24)}$. The improvements after gamma knife anterior capsulotomy were noted in $55 \%$ to $70 \%$ of patients ${ }^{24)}$. But the anatomical target localization, dose and collimator selection were varied between the reports. Rück et al. ${ }^{37)}$ compared thermo-capsulotomy and gamma capsulotomy in his series, and reported that same portion of side effects, such as apathy, incontinence, seizure, executive dysfunction, were noted, and very high radiation dose or more than 1 procedure should be avoided. Also the larger target using $8 \mathrm{~mm}$ collimator showed adverse effects of radiation ${ }^{19,31,377}$. Gamma capsulotomy has its own risk of adverse radiation effect other than thermo-capsulotomy, such as radiation necrosis or brain edema or cyst formation ${ }^{37)}$. More than 240 cases of gamma capsulotomy were performed world-widely, and after lowering the maximal dose below $180 \mathrm{~Gy}$, the adverse effects were also diminished ${ }^{20)}$. Also the recent double-blind, randomized controlled trial by Lopes et al. ${ }^{27)}$ showed 58.3\% (7/12) responders after gamma ventral capsulotomy.

\section{Deep brain stimulation (DBS)}

DBS is adjustable and nondestructive procedure which has been demonstrated to be safe in movement disorders. Although the risk of intracerebral hemorrhages is inevitable, the occurrence rates were low as $1-2 \%$ in larger studies including asymptomatic or symptomatic ${ }^{46)}$. The surgical risks still exist, and the implantable pulse generator should be replaced when it is exhausted.

Because of some beneficial overcoming ablative lesioning, there were some trends of DBS to replace lesioning procedures. With very high stimulation strength, DBS was applied in the anterior limb of the internal capsule as lesioning procedure for the first time ${ }^{33)}$. And Nuttin et al. ${ }^{34)}$ reported outcome of DBS for OCD, mean preoperative Y-BOCS score $32.3 \pm 3.9$ to $19.8 \pm 8.0$, and the stimulation effect was maintained for at least 21 months after DBS. The effect of DBS in the internal capsule was limited, and high power was needed which leads high battery consumption. So the DBS target was gradually moved more posteriorly where the anatomical site was close to ventral striatum (VS), ventral capsule (VC), nucleus accumbens, inferior thalamic peduncle and bed nucleus of the stria terminalis ${ }^{16,45)}$. So there were diverse attempts to various targets.

Greenberg et al. ${ }^{12}$ targeted VC/VS, which was slight posterior target than ordinary capsulotomy, where the more compact fibers of CSTC networks are passing. The more posterior the electrode positioned, the less energy (voltage and pulse width) was need. Also the effects of DBS were more prominent in posterior stimulation. The nucleus accumbens was targeted by Sturm et al. which has predominant role in modulating CSTC circuits ${ }^{32)}$. They designed as a double-blind sham-controlled crossover study with unilateral DBS for nucleus accumbens and five patients among 10 showed a decrease of more than $25 \%$ of Y-BOCS score from baseline and 1 greater than 35\% after 1 year ${ }^{15}$. Other study, bilateral nucleus accumbens DBS in 16 patients, by Denys et al. ${ }^{7)}$ showed $47 \%$ and $52 \%$ reduction from baseline Y-BOCS score after 12 and 21 months. Bilateral DBS in inferior thalamic peduncle and in limbic part of subthalamic nucleus are also tried and reported, but included patients are somewhat deviated and small in number ${ }^{16,28}$.

\section{MRgFUS}

The application of focused ultrasound for the lesioning was 
demonstrated in several studies in $1950 \mathrm{~s}^{10,11)}$. Until 1990s, the focused ultrasound was applied under craniectomy condition, because the skull was the major obstacle to make a focal lesion, and also the skull heating due to energy absorption could damage the scalp, bone and adjacent brain parenchyma. The transcranial MR guided focused ultrasound could be used by the development of phased array transducer and advent of MR thermometry ${ }^{21}$. Transcranial MRgFUS is minimum invasive and real-time monitored procedure which has advantage over other surgical technique as radiosurgery or lesioning procedure. Intermittently taking MR imaging could confirm or expect the lesioning during the sonication under MR thermometry, and there are no other ionizing radiation as radiosurgery which should be act as adverse radiation effect. Though the radiofrequency (RF) lesioning procedure has its irreversible characteristics, lesioning with MRgFUS could be adjusted during the procedure. Also there would be no other concern of hardware implantation or replacement or surgical morbidity as DBS.

Recently, the application of MRgFUS for the treatment of various neurological disorders was introduced, but for the psychiatric disorders was first done in our institute since $2013^{18}$. The detailed indication and study protocols are shown in Clin-
icalTrials.gov (NCT01986296). Using 3-T MR (GE Medical Systems, Milwaukee, WI, USA) and ExAblate 4000 system (InSightec, Haifa, Israel), the patient, mounted with CosmanRoberts-Wells stereotactic frame, is attached to the ExAblate 4000 system. After fusioning presonication magnetic resonance imaging and computed tomography, other MR sequences were done to determine the target coordinates. Bilateral anterior limb of internal capsule was targeted from $7 \mathrm{~mm}$ anterior to the anterior margin of the anterior commissure at the same AC-PC plane, extending 2-3 mm along the capsule from a coronal view. Low power sonications were applied to visualize exact position and size of the thermal spot. After confirming the exact targeting, gradual increments of sonication power were applied till the peak temperature exceed $52^{\circ} \mathrm{C}$ for more than 3 seconds. By adjusting target coordinates, about $10 \mathrm{~mm}$ elliptical lesion was created on each side (Fig. 2). During the procedure, especially during cooling time, the patient was asked and examined by a neurosurgeon and a psychiatrist whether there were notable physical or psychological changes. During whole procedure, the patient is fully awake, and after the procedure we monitored for 24 hours as inpatient.

We have reported our preliminary outcome in four patients. Mean baseline Y-BOCS was $35.3 \pm 1.9$ (range, 34-38), and the
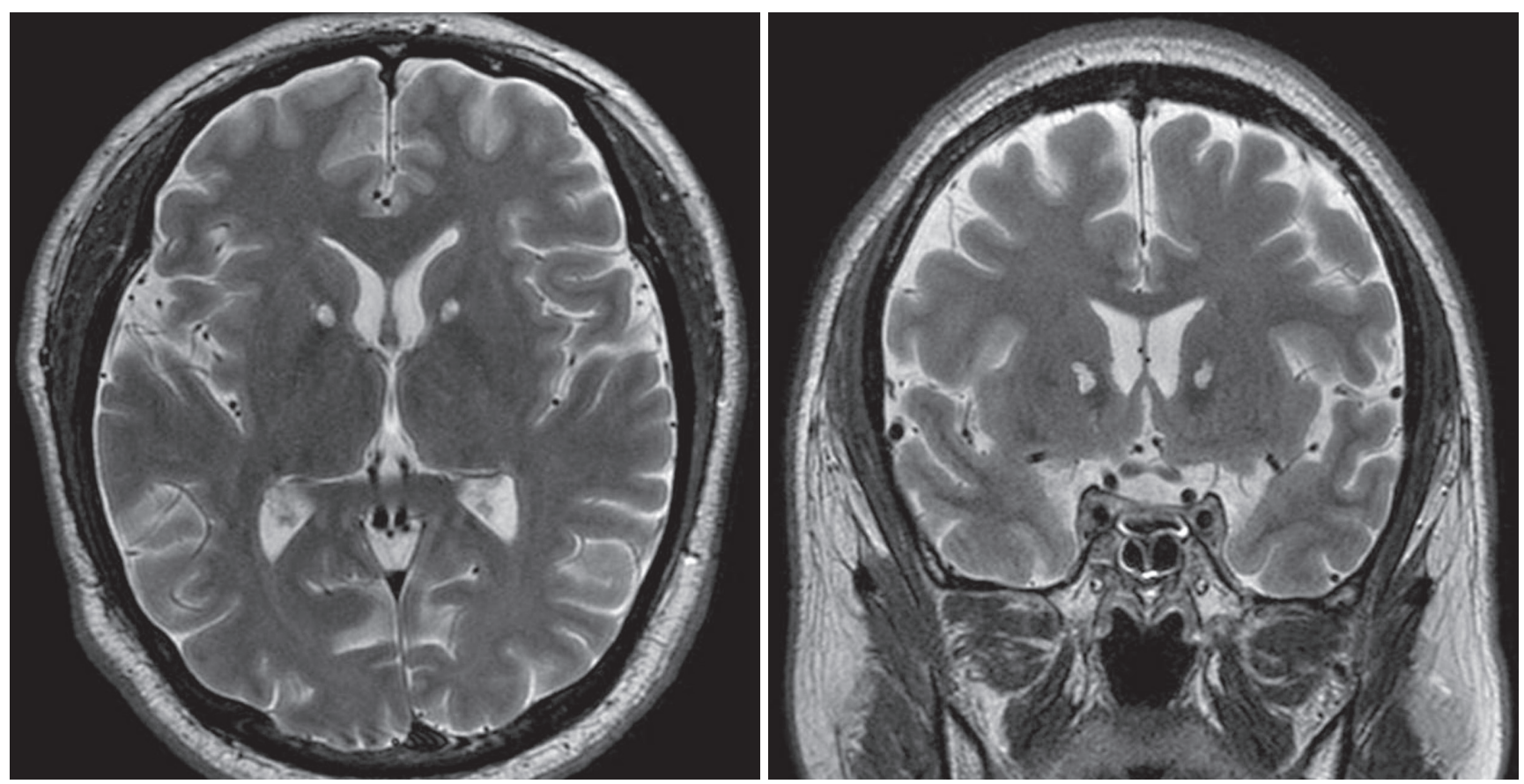

Fig. 2. Postoperative MR images which were taken 6 months after bilateral capsulotomy with MRgFUS. There is no evidence of perilesional edema and the lesion was created exactly in the anterior limb of internal capsule (left : T2WI axial, right: T2WI coronal). MR: magnetic resonance, MRgFUS : magnetic resonance guided focused ultrasound. 


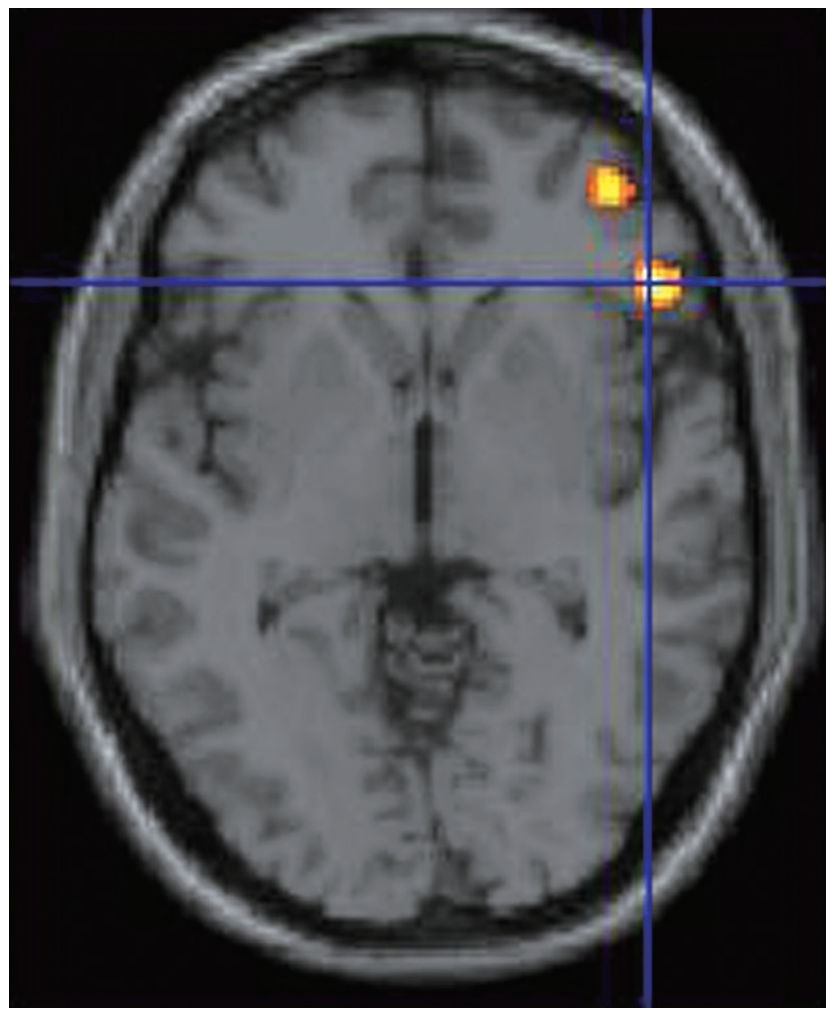

Fig. 3. FDG positron emission tomography (PET) was acquired using high resolution research tomograph-PET (Siemens, Berlin, Germany) from eight patients before and 3 months after MRgFUS. PET images were reconstructed using the ordinary Poisson ordered subset expectation maximization 3D algorithm accelerated by symmetry and single instruction multiple data-based projection and a back-projection algorithm. Statistical parameter mapping software (SPM8, Wellcome Trust Center for Neuroimaging, London, UK) was used for preprocessing and voxel-based statistical processing. The standard uptake value ratio of 18 F-FDG was determined by normalizing the uptake value of each region of interest by the value of each patient's centrum semiovale as a reference region. The orbitofrontal cortex showed decreased uptake significantly $(p<0.001)$. FDG : fludeoxyglucose, MRgFUS : magnetic resonance guided focused ultrasound. mean improvement was 33\% \pm 10.8 (range, 24-47; Y-BOCS, 18-29). Two of four patients met the criteria for a full response during our short-term follow-up, 6 months ${ }^{18)}$. Only transient nausea, vomiting or dizziness was complained by three of four patients during the treatment which could be from longer periods in the MR unit. There were no other procedure related persistent complications. Till now, we enrolled 11 patients and followed up more than 24 months (unpublished). Significant decrease of median Y-BOCS score was noted, 34 to 21, six out of 11 patients were full responder (Y-BOCS score reduction $>35 \%$ ). Also the median the Hamlton Rating Scale for Anxiety (HAM-A) and Depression (HAM-D) scores were also significantly decreased, 19 to 7, 20 to 7, respectively. Neuropsychological tests, such as Wechsler Adult Intelligence Scale-Korean version, Memory Quotient, and Digit Span test-forward scores, were improved and other test, such as Controlled Oral Word Association test, Stroop test, and Digit Span test-backward scores, were unchanged. Compared with a pre-sonication state, high resolution research tomograph-fludeoxyglucose positron emission tomography from the first eight patients showed significantly decreased uptake in the orbitofrontal cortex ( $p<0.001$, Fig. 3).

Using MRgFUS for capsulotomy has some obvious advantages over conventional neurosurgical procedures (Table 1). Apart from non-invasive and non-radiation ablation method, the preciseness and fully monitoring during procedure could minimize the complications related to the procedure. Till now, the application of lesioning with MRgFUS has limitation in selecting previous all the neurosurgical targets for psychological disorders. But the technical development could overcome the limitation of this time era.

Table 1. Comparing with each other characteristics of various therapeutic neurosurgical modalities

\begin{tabular}{|c|c|c|c|c|}
\hline & GKRS & DBS & RF thermal lesioning & MRgFUS \\
\hline Surgical risk (hemorrhage/infection, etc) & - & ++ & +++ & \pm \\
\hline General anesthesia & - & + & \pm & - \\
\hline Hardware complications & - & ++ & - & - \\
\hline Cost & ++ & +++ & + & $?$ \\
\hline Invasiveness of procedure & + & ++ & +++ & + \\
\hline Target accuracy & ++ & + & + & +++ \\
\hline Hospital stay & + & +++ & +++ & $+/++$ \\
\hline Adverse radiation effect & + & - & - & - \\
\hline
\end{tabular}




\section{CONCLUSION}

Though various neurosurgical procedures using RF or gamma knife radiosurgery or DBS showed some benefit to treatment refractory OCD patients, there are still currently an experimental therapy with low level of evidence. Much more prospective studies should be followed, and from these results, the consensus regarding the target or choosing procedures should be made by multidisciplinary teams. With the advent of technological developments, MRgFUS could be one of the procedures for the psychiatric disorder in the near future.

\section{CONFLICTS OF INTEREST}

No potential conflict of interest relevant to this article was reported.

\section{INFORMED CONSENT}

Informed consent was obtained from all individual participants included in this study.

\section{References}

1. Ballantine HT Jr, Bouckoms AJ, Thomas EK, Giriunas IE : Treatment of psychiatric illness by stereotactic cingulotomy. Biol Psychiatry 22 : 807-819, 1987

2. Ballantine HT Jr, Cassidy WL, Flanagan NB, Marino R Jr : Stereotaxic anterior cingulotomy for neuropsychiatric illness and intractable pain. J Neurosurg 26 : 488-495, 1967

3. Björgvinsson $T$, Hart J, Heffelfinger $S$ : Obsessive-compulsive disorder: update on assessment and treatment. J Psychiatr Pract 13 : 362-372, 2007

4. Brown LT, Mikell CB, Youngerman BE, Zhang Y, McKhann GM 2nd, Sheth $S A$ : Dorsal anterior cingulotomy and anterior capsulotomy for severe, refractory obsessive-compulsive disorder: a systematic review of observational studies. J Neurosurg 124 : 77-89, 2016

5. David M, Talairach J, Hecaen $\mathrm{H}$ : Perspectives thérapeutiques issues de la méthode de repérage et de coagulation localisée des structures cérébrales sous-corticales. Bull Mem Soc Med Hop Paris 65 : 459-461, 1949

6. D'Astous M, Cottin S, Roy M, Picard C, Cantin L : Bilateral stereotactic anterior capsulotomy for obsessive-compulsive disorder: long-term followup. J Neurol Neurosurg Psychiatry 84 : 1208-1213, 2013

7. Denys $D$, Mantione $M$, Figee $M$, van den Munckhof $P$, Koerselman $F$, West-

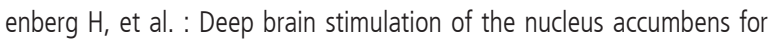

treatment-refractory obsessive-compulsive disorder. Arch Gen Psychiatry 67 : 1061-1068, 2010

8. Dunsmore RH, Lennox MA : Stimulation and strychninization of supracallosal anterior cingulate gyrus. J Neurophysiol 13 : 207-214, 1950

9. Foltz EL, White LE Jr : Pain "relief" by frontal cingulumotomy. J Neurosurg $19: 89-100,1962$

10. Fry WJ, Barnard JW, Fry FJ, Brennan JF : Ultrasonically produced localized selective lesions in the central nervous system. Am J Phys Med 34 : 413-423, 1955

11. Fry WJ : Intense ultrasound in investigations of the central nervous system. Adv Biol Med Phys 6 : 281-348, 1958

12. Greenberg BD, Malone DA, Friehs GM, Rezai AR, Kubu CS, Malloy PF, et al. : Three-year outcomes in deep brain stimulation for highly resistant obsessive-compulsive disorder. Neuropsychopharmacology 31 : 2384-2393, 2006

13. Gross D, Schäfer G : Egas Moniz (1874-1955) and the "invention" of modern psychosurgery: a historical and ethical reanalysis under special consideration of portuguese original sources. Neurosurg Focus 30 : E8, 2011

14. Hassenbusch SJ, Pillay PK, Barnett GH : Radiofrequency cingulotomy for intractable cancer pain using stereotaxis guided by magnetic resonance imaging. Neurosurgery $27: 220-223,1990$

15. Huff W, Lenartz D, Schormann M, Lee SH, Kuhn J, Koulousakis A, et al. : Unilateral deep brain stimulation of the nucleus accumbens in patients with treatment-resistant obsessive-compulsive disorder: outcomes after one year. Clin Neurol Neurosurg 112 : 137-143, 2010

16. Jimenez-Ponce F, Velasco-Campos F, Castro-Farfán G, Nicolini H, Velasco AL, Salín-Pascual $R$, et al. : Preliminary study in patients with obsessivecompulsive disorder treated with electrical stimulation in the inferior thalamic peduncle. Neurosurgery 65(6 Suppl) : 203-209; discussion 209, 2009

17. Jung HH, Kim CH, Chang JH, Park YG, Chung SS, Chang JW : Bilateral anterior cingulotomy for refractory obsessive-compulsive disorder: longterm follow-up results. Stereotact Funct Neurosurg 84 : 184-189, 2006

18. Jung HH, Kim SJ, Roh D, Chang JG, Chang WS, Kweon EJ, et al. : Bilateral thermal capsulotomy with mr-guided focused ultrasound for patients with treatment-refractory obsessive-compulsive disorder: a proof-of-concept study. Mol Psychiatry 20 : 1205-1211, 2015

19. Kihlström L, Hindmarsh T, Lax I, Lippitz B, Mindus P, Lindquist C : Radiosurgical lesions in the normal human brain 17 years after gamma knife capsulotomy. Neurosurgery 41 : 396-401; discussion 401-402, 1997

20. Kondziolka D, Flickinger JC, Hudak R : Results following gamma knife radiosurgical anterior capsulotomies for obsessive compulsive disorder. Neurosurgery 68 : 28-32; discussion 23-33, 2011

21. Kyriakou A, Neufeld E, Werner B, Paulides MM, Szekely G, Kuster N : A review of numerical and experimental compensation techniques for skullinduced phase aberrations in transcranial focused ultrasound. Int J Hyperthermia $30: 36-46,2014$

22. Laitinen L, Toivakka E, Vilkki I : Rostral cingulotomy for mental disorders (electrophysiologic, psychological and clinical findings). Vopr Neirokhir 37 : 23-30, 1973

23. Leksell L: Stereotactic radiosurgery. J Neurol Neurosurg Psychiatry 46 : 
797-803, 1983

24. Lévêque $M$, Carron R, Régis J : Radiosurgery for the treatment of psychiatric disorders: a review. World Neurosurg 80 : \$32.e1-e9, 2013

25. Lippitz B, Mindus P, Meyerson BA, Kihlstrom L, Lindquist C : Obsessive compulsive disorder and the right hemisphere: topographic analysis of lesions after anterior capsulotomy performed with thermocoagulation. Acta Neurochir Suppl $68: 61-63,1997$

26. Liu K, Zhang H, Liu C, Guan Y, Lang L, Cheng Y, et al. : Stereotactic treatment of refractory obsessive compulsive disorder by bilateral capsulotomy with 3 years follow-up. J Clin Neurosci 15 : 622-629, 2008

27. Lopes AC, Greenberg BD, Canteras MM, Batistuzzo MC, Hoexter MQ, Gentil AF, et al. : Gamma ventral capsulotomy for obsessive-compulsive disorder: a randomized clinical trial. JAMA Psychiatry 71 : 1066-1076, 2014

28. Mallet L, Polosan M, Jaafari N, Baup N, Welter ML, Fontaine D, et al. : Subthalamic nucleus stimulation in severe obsessive-compulsive disorder. $\mathbf{N}$ Engl J Med 359 : 2121-2134, 2008

29. McGovern RA, Sheth $\mathrm{SA}$ : Role of the dorsal anterior cingulate cortex in obsessive-compulsive disorder: converging evidence from cognitive neuroscience and psychiatric neurosurgery. J Neurosurg 126 : 132-147, 2017

30. Mettler FA : A comparison between various forms of psychosurgery. $\mathbf{N} \mathbf{Y}$ State J Med 49 : 2283-2286, 1949

31. Mindus $P$, Bergström K, Levander SE, Norén G, Hindmarsh T, Thuomas $K A$ : Magnetic resonance images related to clinical outcome after psychosurgical intervention in severe anxiety disorder. J Neurol Neurosurg Psychiatry 50 : 1288-1293, 1987

32. Nicola SM : The nucleus accumbens as part of a basal ganglia action selection circuit. Psychopharmacology (Berl) 191 : 521-550, 2007

33. Nuttin B, Cosyns P, Demeulemeester H, Gybels J, Meyerson B : Electrical stimulation in anterior limbs of internal capsules in patients with obsessive-compulsive disorder. Lancet 354 : 1526, 1999

34. Nuttin BJ, Gabriëls LA, Cosyns PR, Meyerson BA, Andréewitch $S$, Sunaert $S G$, et al. : Long-term electrical capsular stimulation in patients with obsessive-compulsive disorder. Neurosurgery 52 : 1263-1272; discussion 1272-1274, 2003

35. Oliver B, Gascón J, Aparicio A, Ayats E, Rodriguez R, Maestro De León JL, et al. : Bilateral anterior capsulotomy for refractory obsessive-compulsive disorders. Stereotact Funct Neurosurg 81 : 90-95, 2003

36. Rodman AM, Milad MR, Deckersbach T, Im J, Chou T, Dougherty DD : Neuroimaging contributions to novel surgical treatments for intractable obsessive-compulsive disorder. Expert Rev Neurother 12 : 219-227, 2012

37. Rück C, Karlsson A, Steele JD, Edman G, Meyerson BA, Ericson K, et al. : Capsulotomy for obsessive-compulsive disorder: long-term follow-up of 25 patients. Arch Gen Psychiatry 65 : 914-921, 2008

38. Saxena S, Rauch SL : Functional neuroimaging and the neuroanatomy of obsessive-compulsive disorder. Psychiatr Clin North Am 23 : 563-586, 2000

39. Scoville WB : Selective cortical undercutting as a means of modifying and studying frontal lobe function in man; preliminary report of 43 operative cases. J Neurosurg 6 : 65-73, 1949

40. Sheth SA, Neal J, Tangherlini F, Mian MK, Gentil A, Cosgrove GR, et al. : Limbic system surgery for treatment-refractory obsessive-compulsive disorder: a prospective long-term follow-up of 64 patients. J Neurosurg 118 : 491-497, 2013

41. Skoog G, Skoog I : A 40-year follow-up of patients with obsessive-compulsive disorder. Arch Gen Psychiatry 56 : 121-127, 1999

42. Spiegel EA, Wycis HT : Effect of 3-orthotoloxy-1,2-propanediol (tolserol, myanesin) upon electrogram of human cortex and subcortex. Proc Soc Exp Biol Med 72 : 446-448, 1949

43. Steketee G, Frost RO, Cohen I : Beliefs in obsessive-compulsive disorder. J Anxiety Disord 12 : 525-537, 1998

44. van den Heuvel OA, van der Werf YD, Verhoef KM, de Wit S, Berendse HW, Wolters ECh, et al. : Frontal-striatal abnormalities underlying behaviours in the compulsive-impulsive spectrum. J Neurol Sci 289 : 55-59, 2010

45. van Kuyck K, Brak K, Das J, Rizopoulos D, Nuttin B : Comparative study of the effects of electrical stimulation in the nucleus accumbens, the mediodorsal thalamic nucleus and the bed nucleus of the stria terminalis in rats with schedule-induced polydipsia. Brain Res 1201 : 93-99, 2008

46. Videnovic A, Metman LV : Deep brain stimulation for parkinson's disease: prevalence of adverse events and need for standardized reporting. Mov Disord $23: 343-349,2008$

47. Vos T, Mathers CD : The burden of mental disorders: a comparison of methods between the Australian burden of disease studies and the global burden of disease study. Bull World Health Organ 78 : 427-438, 2000

48. Whitty CW, Duffield JE, Tov' PM, Cairns $H$ : Anterior cingulectomy in the treatment of mental disease. Lancet 1 : 475-481, 1952 